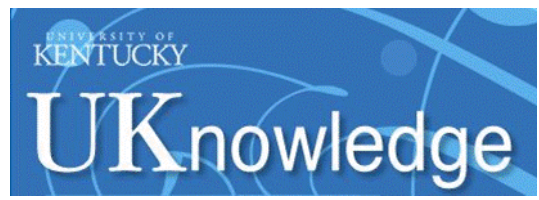

University of Kentucky

UKnowledge

Biosystems and Agricultural Engineering

Faculty Publications

Biosystems and Agricultural Engineering

1980

\title{
Ground Driven Powered Tillage
}

\author{
Larry G. Wells \\ University of Kentucky, larry.wells@uky.edu \\ E. M. Smith \\ University of Kentucky \\ D. E. Hammett \\ Durand-Wayland, Inc. \\ H. J. Thompson Jr. \\ University of Kentucky
}

Follow this and additional works at: https://uknowledge.uky.edu/bae_facpub

Part of the Agriculture Commons, Bioresource and Agricultural Engineering Commons, and the Soil

Science Commons

Right click to open a feedback form in a new tab to let us know how this document benefits you.

\section{Repository Citation}

Wells, Larry G.; Smith, E. M.; Hammett, D. E.; and Thompson, H. J. Jr., "Ground Driven Powered Tillage" (1980). Biosystems and Agricultural Engineering Faculty Publications. 192.

https://uknowledge.uky.edu/bae_facpub/192

This Article is brought to you for free and open access by the Biosystems and Agricultural Engineering at UKnowledge. It has been accepted for inclusion in Biosystems and Agricultural Engineering Faculty Publications by an authorized administrator of UKnowledge. For more information, please contact UKnowledge@lsv.uky.edu. 


\section{Ground Driven Powered Tillage}

Digital Object Identifier (DOI)

https://doi.org/10.13031/2013.34784

Notes/Citation Information

Published in Transactions of the ASAE, v. 23, issue 6, p. 1383-1387.

(C) 1980 American Society of Agricultural Engineers

The copyright holder has granted the permission for posting the article here.

This article is available at UKnowledge: https://uknowledge.uky.edu/bae_facpub/192 


\title{
Ground Driven Powered Tillage
}

\author{
L. G. Wells, E. M. Smith, D. E. Hammett, H. J. Thompson, Jr.

$\begin{array}{cc}\text { MEMBER } & \text { ASSOC. } \\ \text { ASAE } & \text { MEMBER } \\ & \text { ASAE }\end{array}$

$\begin{array}{cc}\text { ASSOC. } & \text { STUDENT } \\ \text { MECH. } & \text { MEMBER } \\ \text { MEMBER } & \text { ASAE } \\ \text { ASAE } & \end{array}$

ABSTRACT

A ground driven powered tillage device is described which utilizes a passive rolling coulter propelled through the soil by a prime mover. The reaction torque imparted by the soil to the coulter is delivered via a torque transfer unit to a powered tillage blade. The tillage blade rotates counter to the direction of the passive rolling coulter and prepares a tilled furrow of some predetermined depth for seed placement and coverage.

Analysis is presented in which the torque developed by a passive rolling coulter engaging the soil is predicted. A relationship is presented for determining the velocity ratio between the coulter and tillage blade. Finally, the shape and number of teeth a tillage blade has is expressed in terms of tillage depth and speed of the tillage blade.

\section{INTRODUCTION}

In 1975, the Agricultural Engineering Department at the University of Kentucky initiated research to adapt the powered tillage concept to so-called "no-till" row crop planters. "No-till" is a term which has been used to describe row crop planters that are used to plant crops such as corn and soybeans in fields which have not been tilled by plowing or disking. The use of this term is somewhat misleading because such planters must have a tillage device for each planting unit so that the seeds can be placed into the soil at the proper depth. Conventional row crop planters do not require this tillage device because the fields are tilled by plowing and/or disking before the planter is used.

A mechanism which uses a passive coulter to provide the power to drive a powered tillage blade has been designed and tested by researchers at the University of Kentucky. This mechanism could make the powered tillage system adaptable to "no-till" planting operations and could allow "no-till" planters to be used for certain crops and field conditions presently excluded because of inadequate tillage devices.

\section{DESCRIPTION OF THE DEVICE}

Fig. 1 shows one concept of the ground-driven

Article was submitted for publication in September 1979; reviewed and approved for publication by the Power and Machinery Division of ASAE in February 1980. Presented as ASAE Paper No. 79-1024.

The investigation reported in this paper (79-2-111) is in connection with a project of the Kentucky Agricultural Experiment Station and is published with the approval of the Director.

The device described in this paper has been patented - United States Patent No. 4,136,744.

The authors are: L. G. WELLS, Associate Professor, E. M. SMITH, Professor, Agricultural Engineering Dept., University of Kentucky; D. E. HAMMETT, Design Engineer, Durand-Wayland, Inc., La Grange, GA; and H. J. THOMPSON, JR., Student, Agricultural Engineering Dept., University of Kentucky, Lexington.

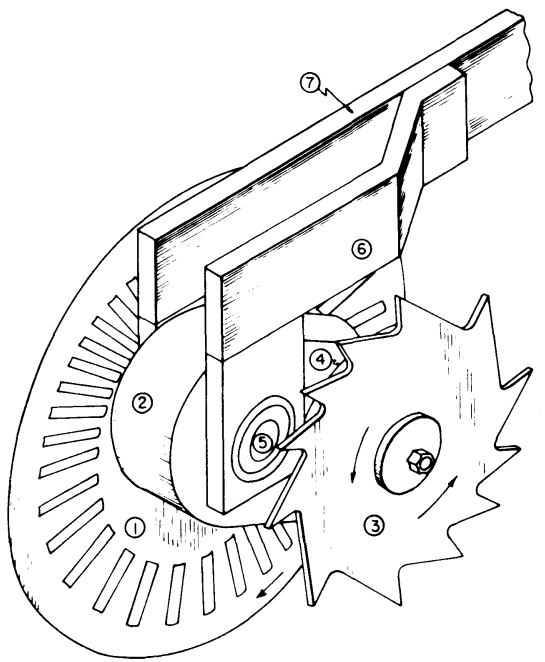

FIG 1. Illustration of ground driven powered tillage blade assembly: (1) passive rolling coulter, (2) torque transfer unit, (3) powered tillage blade, (4) concentric depth band, (5) coulter shaft, (6) mounting frame, and (7) mounting position for compression spring.

powered tillage device. A rolling coulter (1) is propelled by the machine to which the device is attached, and the torque developed by the coulter as it rolls is transferred by gears and/or chains in a torque transfer unit (2) to a powered tillage blade (3). The depth of tillage is controlled by a concentric depth band (4) which floats the powered tillage blade (3) about the coulter shaft (5). A suitable frame (6) attaches the device to a host machine such that the entire device can float up and down to follow uneven soil surfaces as the host machine is propelled over a field to be tilled. A spring (7) is attached to the device and to the frame of the host machine to provide adequate down pressure to keep the rolling coulter (1) turning so that sufficient torque will be available to turn the powered tillage blade.

Even though a rolling coulter (1) is shown on the attached sketch, the torque could be developed by using a variety of disks or wheels, some of which are presently used on farm machines. The attached sketch shows an offset relationship between the rolling coulter (1) and the powered tillage blade (3), however the rolling torque developing device could also be placed directly in front of the powered tillage blade, or the rolling torque developing device could be placed directly behind the powered tillage blade. The torque can be transferred to the powered tillage blade such that the torque developing device and the powered tillage blade turn in opposite directions or in the same direction.

Most contemporary "no-till" planters employ a passive rolling coulter as the tillage device. A passive rolling coulter is totally dependent upon weight to obtain 
penetration into the soil, consequently, "no-till" planters have to be heavier than conventional planters. Passive rolling coulters provide practically no relative motion between the coulter and the soil; it presses a furrow into the soil as it rolls along. Some relative motion (cutting action) between the soil and the passive rolling coulter can be obtained by shaping flutes around the periphery of the coulter. However, the fluted passive coulter requires even more weight to obtain penetration into the soil.

Powered tillage allows the designer to control the relative motion between the cutting edges on the tillage blade and the soil. The powered tillage blade is a tillage device which cuts (shears), lifts and pulverizes layers of soil to make a furrow of some predetermined depth to receive seeds. The lifted and pulverized soil can be used to cover the seeds. The shearing and lifting action of the powered tillage blades greatly reduces the weight necessary to obtain penetration as compared with the passive rolling coulter, which depends totally upon weight to obtain penetration.

The greatest problem encountered in making the powered tillage blade compatible with row planting has been to develop a method of transferring power from the prime mover (tractor) to the tillage blade. Each tillage blade needs to be independently suspended and independently driven so that it can follow an uneven soil surface. Mechanical drive trains, electric motors, and hydraulic motors have been tested and will function satisfactorily. All of these methods, however, experience power losses in making the transfer and are relatively expensive when compared with the passive rolling coulter.

\section{DIRECTION OF ROTATION OF THE POWERED TILLAGE BLADE}

Smith and Hammett (1977) showed that a powered tillage blade should rotate in a direction opposite to the direction of rotation of the passive rolling coulter. The opposite direction of rotation gives a higher velocity of each cutting edge on the blade relative to the soil at a lower angular velocity of the blade than when the blade is rotated in the same direction as the passive rolling coulter. The opposite direction of rotation also accelerates each cutting edge in an upward direction as it moves through the soil and lifts the soil out of the resulting furrow. If a blade is rotated in the same direction as the passive rolling coulter, each cutting edge would accelerate downward and tend to compress the soil toward the bottom of the furrow. The angular velocity of the powered tillage blade can be much lower when the blade is rotated opposite to the direction of the passive rolling coulter. For example, if one operates a powered tillage blade which is $30.48 \mathrm{~cm}$ in diameter at a ground speed of $7.24 \mathrm{~km} / \mathrm{h}$, an angular velocity of $126 \mathrm{r} / \mathrm{min}$ in a direction opposite to the rolling coulter and at a tillage depth of $7.62 \mathrm{~cm}$ each cutting edge of the powered tillage blade makes approximate initial contact with the soil at a horizontal velocity relative to the soil of (Fig. 4):

$$
\mathrm{v}_{\mathrm{h}}=\mathrm{v}_{\mathrm{c}} \pm \mathrm{v}_{\mathrm{t}} \cos \theta \ldots \ldots \ldots \ldots \ldots \ldots \ldots \ldots \ldots \ldots
$$

where

$$
\begin{aligned}
& \mathrm{V}_{\mathrm{c}}= 7.24 \mathrm{~km} / \mathrm{h}=\text { horizontal velocity of center } \\
& \text { of rotation, }
\end{aligned}
$$

and thus

$$
\text { rotation }(0 \mathrm{deg}) \text {, }
$$

$$
\mathrm{V}_{h}=7.24+7.24=14.48 \mathrm{~km} / \mathrm{h}
$$

With a tooth spacing of $30 \mathrm{deg}$ each cutting edge of the powered tillage blade would exit the soil at a horizontal velocity of

$$
V_{h}=7.24+7.24 \cos \left(60^{\circ}\right)=10.86 \mathrm{~km} / \mathrm{h}
$$

In contrast, if the same powered tillage blade was rotated in the same direction as the rolling coulter and each cutting edge initially engaged the soil at a horizontal velocity relative to the soil of $10.86 \mathrm{~km} / \mathrm{h}$, the angular velocity of the powered tillage blade would have to be $630 \mathrm{r} / \mathrm{min}$, i.e., five times as great as the angular velocity when the blade is rotated opposite to the direction of the rolling coulter. The lower angular velocity can be quite significant in terms of reducing wear on the cutting edges of the powered tillage blade.

Another advantage of rotating the powered tillage blade in a direction opposite to the rotation of the rolling coulter is that the torque delivered by the coulter opposes the torque required by the powered tillage blade. In effect, the units are locked by opposing forces so that if the rolling coulter stalls and slips in the soil, the blade will continue to till the soil much like a rigid shank tillage tool. On the other hand, if the powered tillage blade was rotated in the same direction as the rolling coulter, stall and slip of the coulter would allow the blade to roll and not till the soil.

\section{TORQUE DEVELOPED BY A COULTER}

The magnitude and direction of the normal force $(\mathrm{N})$ exerted on the soil depend upon the external forces applied to the coulter and are given by the vector equation:

$$
\overline{\mathbf{N}}=\overline{\mathbf{Q}} \rightarrow \overline{\mathbf{P}}
$$

where

$$
\begin{aligned}
\overline{\mathrm{N}}= & \text { the normal force exerted on the soil, } \\
\overline{\mathrm{Q}}= & \text { the weight force (vertical direction), } \\
\overline{\mathrm{P}}= & \text { the pull force (horizontal direction), and } \\
& \text { the operate " } \rightarrow \text { " indicates vector addition. }
\end{aligned}
$$

From equation [2] and the Law of Cosines, we have:

$$
\mathrm{N}^{2}=\mathrm{Q}^{2}+\mathrm{P}^{2}-2 \mathrm{QP} \cos \gamma
$$

Since $\overline{\mathrm{Q}}$ and $\overline{\mathrm{P}}$ are orthogonal vectors, $\gamma$, the angle between them, equals $90 \mathrm{deg}$. Therefore,

$$
N=\sqrt{Q^{2}+P^{2}}
$$

We can determine the direction of the normal force by using the Law of Sines,

$$
\frac{\sin \gamma}{\mathrm{N}}=\frac{\sin \alpha}{\mathrm{Q}}
$$

Once again we noted that $\gamma$ equals $90 \mathrm{deg}$ so:

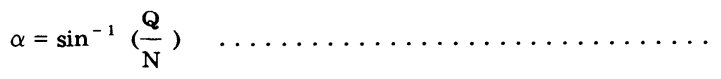

where

$\alpha=$ angular displacement of the normal force measured downward from the horizontal centerline of the coulters point of rotation (Fig. 2a). 


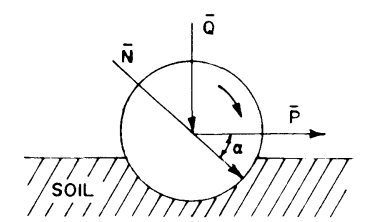

(a) Resultant $(\bar{N})$ of horizontal pull (P) and vertical weight ( $\overline{\mathrm{Q}}$ ) acting on coulter axle

(b) Soil reaction $(\overline{\mathrm{N}})$ and tangential friction component $(\bar{f})$ acting on coulter

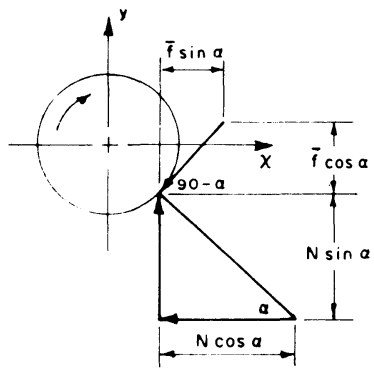

(c) Horizontal and vertical components of soil reaction $(\bar{N})$ and tangential friction $(\bar{f})$ forces

FIG. 2 Forces acting on a passive rolling coulter engaging in a soil profile.

We know the magnitude and direction of the normal force exerted on the soil by the coulter. We also know that the normal force exerted by the soil on the coulter must be exactly equal in magnitude and opposite in direction. If we denote the normal soil reaction force by $\bar{N}^{\prime}$, then $\mathbf{N}^{\prime}=\mathbf{N}$ and

$$
\overline{\mathbf{N}}=\overline{\mathbf{P}} \nrightarrow \overline{\mathbf{Q}} \nrightarrow \overline{\mathbf{f}}
$$

where

$$
\overline{\mathbf{P}}^{\prime}=\text { the horizontal component of normal force }
$$
which reacts to the pull force, $P$,

$\overline{\mathrm{Q}}^{\prime}=$ the vertical component of normal force which reacts to the weight force, $Q$, and

$\overline{\mathrm{f}}=$ component of the normal reaction force due to all frictional and shearing forces acting in a direction tangential to the coulter and in the direction of the impending motion of the coulter (Fig. 2b).

We have a formula from vector mechanics for the magnitude of the friction component:

$\mathbf{f}=\mu \mathrm{N}^{\prime}$

where

$\mu=$ the coefficient of friction (a predetermined value should be available).

To find the magnitudes of $\overline{\mathrm{P}}^{\prime}$ and $\overline{\mathrm{Q}}^{\prime}$ we resolve the vector $\bar{f}$ and $\bar{N}$ into horizontal $(x)$ and vertical (y) components (Fig. 2c).

x-direction: $\mathbf{N} \cos \alpha-\mathbf{f} \sin \alpha=\mathbf{P}^{\prime} \ldots \ldots \ldots \ldots \ldots$

y-direction: $\mathrm{N} \sin \alpha+\mathrm{f} \cos \alpha=\mathbf{Q}^{\prime}$

Combining equations [6] and [7] yields:

$$
\begin{aligned}
& \mathbf{P}^{\prime}=\mathrm{N}(\cos \alpha-\mu \sin \alpha) \\
& \mathbf{Q}^{\prime}=\mathrm{N}(\sin \alpha+\mu \cos \alpha)
\end{aligned}
$$

Bernacki (1972) states that the normal force exerted by the soil "is applied to the coulter blade at the midpoint of the depth of tillage." Thus, we have

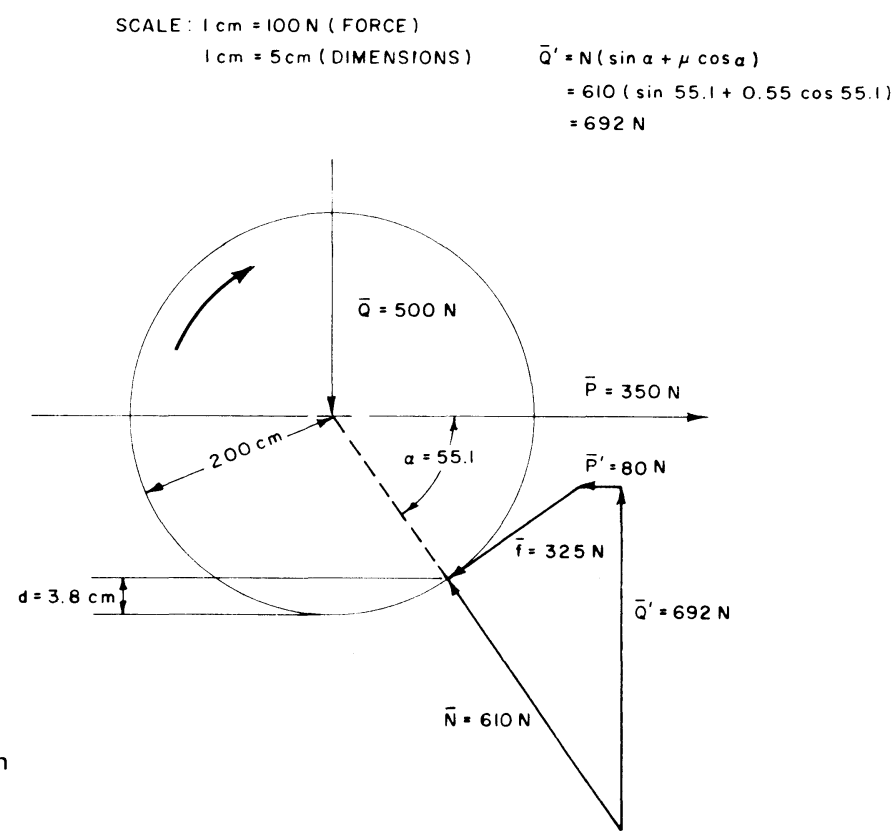

FIG. 3 Graphical solution of an example problem involving a passive rolling coulter engaged in a soil profile.

$$
\mathrm{d}=\mathbf{R}(1-\sin \alpha)
$$

where

$$
\begin{aligned}
& \mathrm{d}=\quad \begin{array}{l}
\text { distance from bottom of the coulter blade } \\
\text { to the point of application of the normal }
\end{array} \\
& \text { force, and } \\
& \mathrm{F}=\text { radius of the coulter (Fig. } 2 \mathrm{~d} \text { ) }
\end{aligned}
$$

The depth at which the coulter blade runs in the soil is by assumption equal to $2 \mathrm{~d}$.

Finally, we wish to know the amount of torque provided by the rolling coulter:

$$
\mathrm{T}=\mathbf{f R}
$$

where,

$$
\begin{aligned}
& \mathrm{T}=\text { the torque provided by the friction compo- } \\
& \text { nent multiplied by the moment arm which } \\
& \text { is the radius of the coulter. }
\end{aligned}
$$

\section{EXAMPLE}

We desire to know the magnitude and direction of the normal force acting on the soil if a rolling coulter is pulled along with a $350 \mathrm{~N}$ force and the coulter has a $500 \mathrm{~N}$ force acting downward on its center of rotation. Assuming the coulter has a radius of $20 \mathrm{~cm}$ and the coefficient of friction, $\mu$, is 0.55 , we also desire to know the magnitude of the torque provided by the coulter.

The graphical solution of this problem is shown in Fig. 3 and the results are as follows: $\mathrm{P}=350 \mathrm{~N}, \mathrm{Q}=500 \mathrm{~N}, \mathrm{~N}$ $=610 \mathrm{~N}, \mathrm{X}=55.1^{\circ}, \mathrm{d}=3.8 \mathrm{~cm}, \mathrm{P}^{\prime}=80 \mathrm{~N}, \mathrm{Q}^{\prime}=$ $692 \mathrm{~N}, \mathrm{f}=325 \mathrm{~N}, \mathrm{~T}=84 \mathrm{~J}$.

\section{RELATIVE DIAMETERS OF COULTER AND TILLAGE BLADE}

The passive rolling coulter should be larger than the powered tillage blade to afford a mechanical advantage in the transfer of torque from the coulter to the blade. The ratio of the diameter of the coulter divided by the diameter of the blade should be 1.5 to 2.0 , i.e., the diameter of the coulter should be from 1.5 to 2 times the diameter of the blade. 


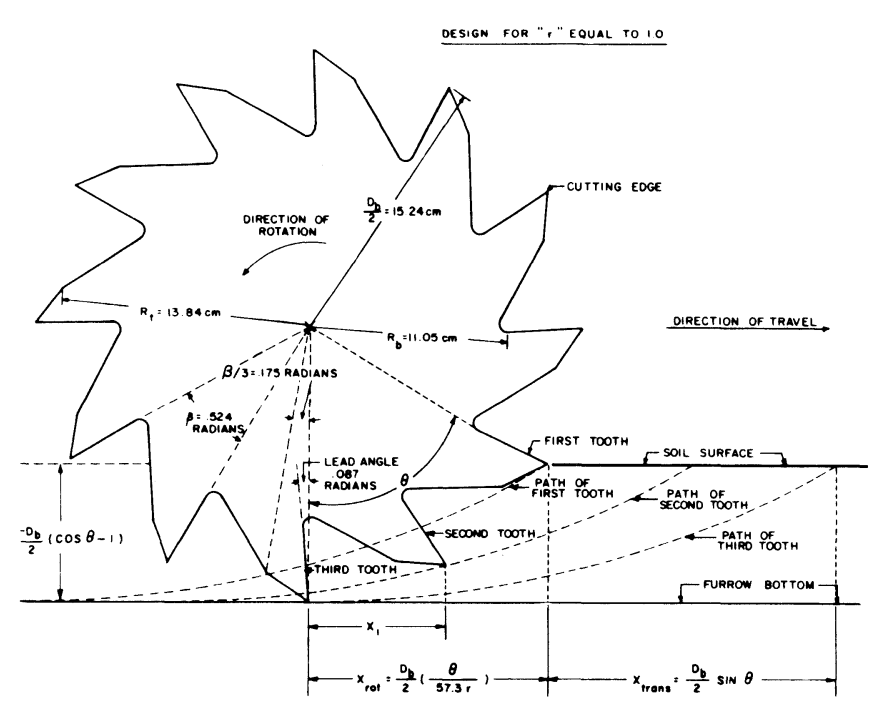

FIG. 4 Powered tillage blade design for a ratio of actual angular velocity to free roll angular velocity (r) of unity and tillage depth of $7.62 \mathrm{~cm}$. where $r$ is the ratio of actual angular velocity to free roll angular veloci$t y, R_{t}$ is the radius to the heel of the cutting edge, and $R_{b}$ is the radius of a base circle from which the cutting teeth are formed.

\section{VELOCITY RATIO BETWEEN COULTER AND TILLAGE BLADE}

The powered tillage blade should be operated between 0.5 and 2.0 times the free roll velocity of the blade. Free roll velocity is attained when the magnitude of the tangential velocity of the blade is equal to the tangential velocity of the coulter. The velocity ratio between the coulter and the blade is as follows:

$$
\mathrm{v}_{\mathrm{r}}=\frac{\mathrm{D}_{\mathrm{b}}}{\mathrm{D}_{\mathrm{c}^{r}}}
$$

where

$$
\begin{aligned}
& \mathrm{V}_{r}=\text { velocity ratio between the coulter and the } \\
& \mathrm{D}_{b}=\text { diameter of the blade } \\
& D_{c}=\text { diameter of the coulter } \\
& r=\text { desired ratio of angular velocity of the } \\
& \text { blade to its free roll angular velocity. }
\end{aligned}
$$

For example, if the powered tillage blade is to operate at free roll velocity, $r=1$, the diameter of the blade is 12 in., and the diameter of the coulter is 19 in., the velocity ratio between the coulter and the blade should be:

$$
\mathrm{v}_{\mathrm{r}}=\frac{12}{19 \times 1}=0.63
$$

i.e., the coulter should rotate 0.63 revolutions for each revolution of the blade.

\section{DEPTH BAND}

A circular depth band should be mounted adjacent to the powered tillage blade, but it should not be attached to the blade. The band should be located so that its axis is vertically in line with the axis of rotation of the power tillage blade. The depth band should be attached so that it can be adjusted up and down to obtain a desired depth of tillage. The diameter of the circular depth band should not be less than one-half the diameter of the blade.

A free rolling wheel can be used as a depth gauge instead of a circular depth band. The wheel should also be mounted so that its axis of rotation is vertically in line with the axis of rotation of the blade. The wheel should maintain this alignment as it is adjusted up and down to obtain a desired depth of tillage.

\section{TOOTH SHAPE AND NUMBER OF TEETH ON THE POWERED TILLAGE BLADE}

The path followed by a cutting edge on the powered tillage blade as it moves through the soil depends upon the ratio of the angular velocity of the blade divided by the free roll angular velocity of the blade and the diameter of the blade. The following parametric equations define the path followed by a cutting edge as it moves through the soil:

$$
\begin{aligned}
& \mathrm{X}=\frac{\mathrm{D}_{\mathrm{b}}}{2}\left[\frac{\theta}{57.3 \mathrm{r}}+\sin (\theta)\right] \ldots \ldots \ldots \ldots \ldots \ldots \ldots \ldots \ldots \\
& Y=\frac{-D_{b}}{2}[\cos (\theta)-1]
\end{aligned}
$$

where

$X=$ horizontal displacement of a cutting edge on the blade from a position vertically beneath the center of rotation of the blade, $\mathrm{cm}$

$\mathrm{Y}=$ vertical displacement of a cutting edge on the blade from a position vertically beneath the center of rotation of the blade, $\mathrm{cm}$

$\mathrm{D}_{b}=$ diameter of the blade, $\mathrm{cm}$

$r=$ ratio of the angular velocity of the blade divided by the free roll angular velocity of the blade

$\theta=$ angular displacement of the cutting edge measured from a point vertically beneath the center of rotation of the blade, deg

Succeeding cutting edges will follow the same shape path and will engage the soil $(\theta=0)$ after the center of rotation of the blade has moved a horizontal distance equal to:

$$
\mathrm{X}_{1}=\frac{\mathrm{D}_{\mathrm{b}}}{2}\left[\frac{\beta}{57.3 \mathrm{x}}\right]
$$

where

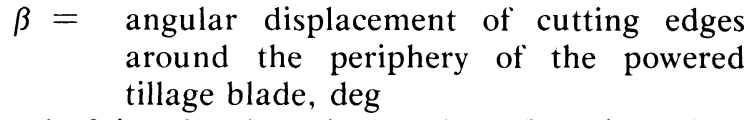

The angle $\beta$ is related to the number of cutting edges around the periphery of the blade by:

$$
\beta=\frac{360}{n}
$$

where

$\mathrm{n}=$ number of cutting edges on the powered tillage blade.

Each cutting edge on the powered tillage blade should be able to follow its path through the soil without interference from other parts of the blade. Adequate clearance angles must be provided on the leading and trailing faces of each cutting edge. 
The leading face from each cutting edge should form an angle of $5 \mathrm{deg}<l<20 \mathrm{deg}$ with a radial line from the center of rotation of the blade to the cutting edge. This leading face should be behind the radial line and extend from the cutting edge to a base circle whose radius from the center of rotation of the blade is as follows:

$$
\mathrm{R}_{\mathrm{b}} * \frac{\frac{\mathrm{D}_{\mathrm{b}}}{2}\left[\frac{\phi-\beta}{57.3 \mathrm{r}}+\sin \phi\right]}{\frac{\phi}{57.3 \mathrm{r}}+\sin \phi}
$$

where

$$
\begin{aligned}
\mathbf{R}_{b}= & \begin{array}{l}
\text { radius of a base circle from which the cut- } \\
\text { ting teeth on a powered tillage blade } \\
\text { should be formed, cm }
\end{array} \\
\phi= & \begin{array}{l}
\text { angular displacement of a cutting edge for } \\
\text { a given depth of tillage, deg }
\end{array}
\end{aligned}
$$

$$
\phi=\cos ^{-1}\left[1-\frac{2 \mathrm{~d}}{\mathrm{D}_{\mathrm{b}}}\right]
$$

where

$$
\mathrm{d}=\text { tillage depth, } \mathrm{cm}
$$

(*If $\mathrm{R}_{b}<\left(\mathrm{D}_{b} / 3\right)$ more teeth should be added to the periphery of the blade so that the base of each tooth will be strong enough to resist the bending moment on the tooth due to transverse forces from the soil.)

The heel of the trailing face should be located on a radial line which forms an angle of $\beta / 3$ with the radial line to the cutting edge. The trailing face then should extend from the cutting edge to a heel defined by a base circle with radius as follows:

$$
R_{t}=\frac{\left[\frac{D_{b}}{2} \frac{\phi-\beta / 3}{57.3 r}+\sin \phi\right]}{\frac{\phi}{57.3 \mathrm{r}}+\sin \phi} \ldots \ldots \ldots \ldots \ldots \ldots \ldots
$$

The tooth shape is completed by constructing an arc, whose radius is $0.476 \mathrm{~cm}$, tangent to the leading face of the adjacent tooth at the point where the leading face intersects with the base circle and extend a line from the heel of the trailing face to a point where this line is tangent to the arc. Blade material is removed between the leading face of each tooth and the trailing face and the line which connects the heel of the arc on the adjacent tooth. The blade thickness should be 0.476 and $1.270 \mathrm{~cm}$, however, the width of the cutting edge on the tooth can be equal to the desired width of the tilled furrow.

Fig. 5 shows a powered tillage blade designed to operated at $63 \mathrm{r} / \mathrm{min}$, at a ground speed of $7.24 \mathrm{~km} / \mathrm{h}$, and at a depth of $7.62 \mathrm{~cm}$ in the soil. The ratio of the actual angular velocity $(63 \mathrm{r} / \mathrm{min})$ of this blade to the free roll angular velocity $(126 \mathrm{r} / \mathrm{min})$ of the blade (4) is 0.5 . The proper clearance angles from the leading and trailing sides of the cutting edge and the paths of three suc-

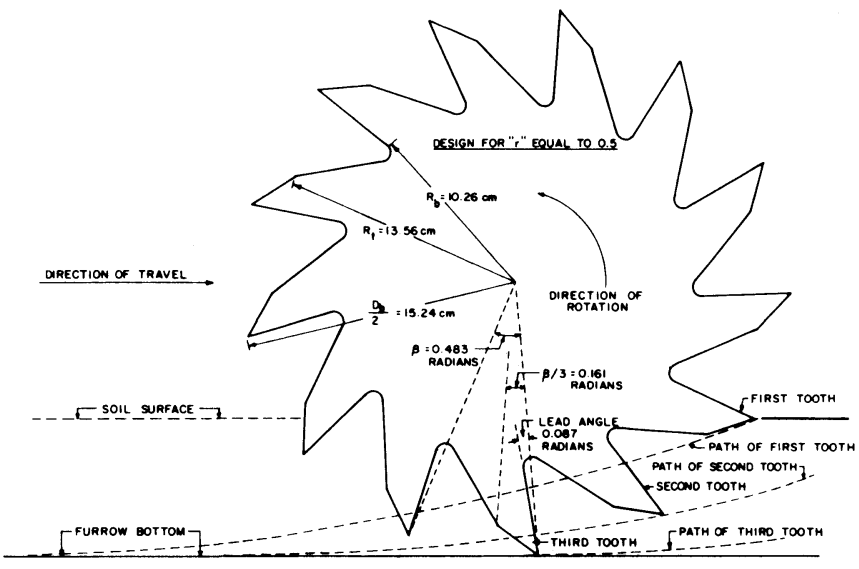

FIG. 5 Powered tillage blade design for a ratio of actual angular velocity to free roll angular velocity (r) of 0.5 and a tillage depth of $7.62 \mathrm{~cm}$, where $r$ is the ratio of actual angular velocity to free roll angular velocity, $R_{t}$ is the radius to the heel of the cutting edge, and $R_{b}$ is the radius of a base circle from which the cutting teeth are formed.

cessive teeth are shown in Fig. 5.

\section{CLOSURE}

A ground driven powered tillage device has been developed which utilizes a passive rolling coulter propelled through the soil by a prime mover. The tillage blade rotates counter to the direction of the coulter and prepares a furrow of predetermined depth for seed placement and coverage. Each blade, drive coulter and corresponding torque transfer unit are individually mounted on a host machine to facilitate operation on rough and uneven terrain.

Analysis has shown the advantage of rotating the powered tillage blade counter to the direction of the passive rolling drive coulter relative to reduction of blade wear and uninterrupted tillage. Torque provided by a rolling coulter was predicted using vector analysis and speed-size relationships between blade and coulter were specified. Finally, analysis was presented whereby the design geometry and number of blade teeth were determined.

\section{References}

1 Bernacki, Henryk, J. Haman and C. Kanafojski. 1972. Agricultural machines - theory and construction. Warsaw, Poland.

2 Smith, Edward M., B. P. Berma and T. H. Taylor. 1967. Energy required to operate a disk furrower in Kentucky bluegrass sod. TRANSACTIONS OF THE ASAE 10:(3):333-336.

3 Smith, E. M., D. H. Bucher and J. B. Hockensmith. 1977. A grassland renovator with a unique tillage device. ASAE Paper No. 77-1002, ASAE, St. Joseph, MI 49085

4 Smith, E. M. and D. E. Hammett. 1977. Analysis and tests of a power tillage blade. ASAE Paper No. 77-1009, ASAE, St. Joseph, MI 49085.

5 Smith, E. M., D. E. Hammett. 1979. Ground driven power tillage device. United States Patent No. 4,136,744, Jan.

6 Smith, E. M., T. H. Taylor, J. H. Casada and W. C. Templeton, Jr. 1973. Experimental grassland renovator. Agronomy Journal 65:506-508, May-June. 